\title{
Climate change impacts on ecologically relevant hydrological indicators in three catchments in three European ecoregions
}

Jens Kiesel 10 https://orcid.org/0000-0002-4371-6434, Andreas Gericke, Hendrik Rathjens, Annett Wetzig, Karan Kakouei, Sonja C. Jähnig (1D https://orcid.org/0000-0002-6349-9561, Nicola Fohrer

DOI

10.1016/i.ecoleng.2018.12.019

Original publication date

21 December 2018 (Available online)

Document version

Accepted manuscript

Published in

Ecological Engineering

\section{Citation (Vancouver)}

Kiesel J, Gericke A, Rathjens H, Wetzig A, Kakouei K, Jähnig SC, Fohrer N. Climate change impacts on ecologically relevant hydrological indicators in three catchments in three European ecoregions. Ecological Engineering. 2019;127:404-16. 


\section{Climate change impacts on ecologically relevant hydrological indicators in three catchments in three European ecoregions}

Jens Kiesel ${ }^{1,2,+}$, Andreas Gericke ${ }^{1}$, Hendrik Rathjens ${ }^{3}$, Annett Wetzig ${ }^{1}$, Karan Kakouei ${ }^{1,4}$, Sonja C. Jähnig ${ }^{1 *}$, Nicola Fohrer $^{2 *}$

${ }^{1}$ Leibniz-Institute of Freshwater Ecology and Inland Fisheries (IGB), Department of Ecosystem Research, Justus-von-Liebig-Str. 7, 12489 Berlin, Germany

${ }^{2}$ Christian-Albrechts-University Kiel, Institute for Natural Resource Conservation, Department of Hydrology and Water Resources Management, Germany

${ }^{3}$ Stone Environmental Inc, 535 Stone Cutters Way, VT 05602, USA

${ }^{4}$ Institute of Biology, Freie Universität Berlin, Berlin, Germany

* These authors contributed equally

${ }^{\dagger}$ Corresponding author. E-mail address: kiesel@igb-berlin.de (J. Kiesel)

\section{ABSTRACT}

Freshwater species are adapted to and depend on various discharge conditions, such as 32 indicators of hydrologic alteration (IHA). Knowing how these indicators will be altered under climate change is essential for predicting species response and to develop mitigation concepts. The simulation of IHA under climate change is subject to considerable uncertainties which should be considered to obtain credible and robust predictions. Therefore, we investigated the major uncertainties inherent in climate change data and processing: General circulation model (GCM) and regional climate model (RCM) choice, representative concentration pathway (RCP) scenario, bias correction (BC) method, all within three mesoscale catchments in the European ecoregions: Central Plains, Central Highlands, and Alpine. Highest uncertainties were caused by the GCM and RCM choice, followed by the type of $B C$ and the RCP. For the prediction, we reduced these uncertainties tailored to the ideal depiction of the IHA in each ecoregion. Together with a significance test, this enabled a robust depiction of the change in IHA for two future time periods. We found diverging changes within the ecoregions, caused by the complex interaction between precipitation, temperature and the governing catchment hydrological processes. The results provide an important basis for further impact research, especially for ecological freshwater studies.

Keywords: climate change, EURO-CORDEX, uncertainty, prediction, hydrological indicators, indicators of hydrologic alteration (IHA)

\section{INTRODUCTION}

Climate change alters the discharge regime of rivers (Nemec and Schaake, 1982, Donnelly et al. 2017) and along with it magnitude, duration, frequency, rate and timing of discharge events. Assessing climate change impacts by indicators such as timing or seasonal flows showed a more robust response as compared to e.g. average annual discharge (Melsen et al. 2018, Addor et al. 2014). Furthermore, freshwater ecosystems have evolved in response to the prevailing discharge regime in streams and rivers (Lytle and Poff, 2004) and are impacted by 
changes to this regime (Domisch et al. 2017, Guse et al. 2015). Therefore, these indicators are increasingly used to predict species distribution (Kakouei et al. 2017) and ecosystem health (Poff and Zimmerman, 2010) due to their comprehensive depiction of the flow conditions.

Simulating changes in streamflow under climate change is subject to considerable uncertainties (Addor et al. 2014, Melsen et al. 2018). Clark et al. (2016) postulate a two-step approach towards dealing with these uncertainties: First, to quantify sources of and second, to develop and apply a method to select combinations of methods and models for less uncertain predictions. Here, we consider uncertainties arising from general circulation model $(\mathrm{GCM})$, regional climate model (RCM) and representative concentration pathway (RCP) selection, and bias correction (BC) method choice as well as the application in three European ecoregions.

The Coordinated Regional Downscaling Experiment (CORDEX, Jacob et al. 2014) provides the most recent and continuously updated, high resolution climate change data for the European continent, coupling the GCM forcing data with RCMs to provide climate parameters on a $0.11^{\circ}$-grid (Kotlarski et al. 2014). Daily data of climate parameters are available for multiple GCM, RCM and RCPs in a harmonized data structure. This makes the CORDEX data an ideal source to assess uncertainties related to the selection of models and scenarios. Climate models often provide biased representations of observed time series, emphasizing the need for bias correction (BC), especially in regional climate scenarios that are used to assess climate change impacts on streamflow using watershed-scale hydrologic models (Muerth et al. 2013). Numerous methods exist (Teutschbein and Seibert, 2012, Wagner et al. 2013), whose application is however critically discussed: Ehret et al. (2012) stress the need to test the uncertainty introduced by different methods, including no BC. In addition, Kotlarski et al. (2014) show that climate models perform differently among ecoregions. No single GCM and RCM was found that performs superior in all regions of Europe and none could be suggested for general use. Therefore, it is necessary to assess the performance of the climate change data in different ecoregions. Additional uncertainties not considered here arise from the selection and parameterization of the hydrological model. For this study, one semi-distributed hydrological model was chosen using one parameterization.

The main objective of this study is a thorough impact analysis of climate change on discharge in rivers, as characterized by ecologically relevant hydrological indicators. It is our aim to obtain robust predictions of changes for two 10yr-periods (2050 and 2090). Therefore, our emphasis lies on identifying and reducing the uncertainties introduced by different representative concentration pathways (here: RCP 4.5 and 8.5), different GCM (here: 5), and RCM (here: 8), bias correction methods for precipitation and temperature, including no bias correction (here: 5) and ecoregional differences by choosing three mesoscale catchments located in three European ecoregions.

\section{METHODOLOGY}

\subsection{Study areas}

We selected three mesoscale river catchments in Germany, from three Central European ecoregions: The Treene in the Central Plains (henceforth "Plains") contains the catchment of the Kielstau, Germany's first UNESCO ecohydrological demonstration site (Fohrer and 
Schmalz, 2012). The Kinzig in the Central Highlands ("Highlands"), is part of the Rhine-MainObservatory

Table 1 Catchment characteristics of the three study catchments

\begin{tabular}{|c|c|c|c|c|}
\hline Catchment characteristic & Unit & Treene & Kinzig & Ammer \\
\hline River basin & - & Eider & Rhine & Danube \\
\hline Ecoregion & - & Central Plains & Central Highlands & Alpine \\
\hline Longitude / Latitude & deg & $9.5 / 54.7$ & $9.3 / 50.3$ & $11.0 / 47.7$ \\
\hline Catchment area & $\mathrm{km}^{2}$ & 477 (non-tidal) & 921 & 608 \\
\hline Elevation gradient & mASL & $4-80$ & $104-624$ & $551-2157$ \\
\hline \multirow[t]{2}{*}{ Major land use classes } & - & Agriculture (48\%) & Forest (45\%) & Forest (47\%) \\
\hline & & Pasture (32\%) & Pasture $(22 \%)$ & Pasture $(37 \%)$ \\
\hline Annual precipitation gradient $*$ & $\mathrm{~mm}$ & $830-944$ & $623-1094$ & $998-1460$ \\
\hline $\begin{array}{l}\text { Temperature daily average } \\
\text { spatial gradient in JJA* }\end{array}$ & ${ }^{\circ} \mathrm{C}$ & $+16.4-+16.6$ & $+17.6-+19.2$ & $+15.8-+17.3$ \\
\hline $\begin{array}{l}\text { Temperature daily average } \\
\text { spatial gradient in DJF * }\end{array}$ & ${ }^{\circ} \mathrm{C}$ & $+1.6-+1.6$ & $+1.3-+2.6$ & $-0.9-+0.1$ \\
\hline Mean runoff rate $*$ & $\mathrm{ls}^{-1} \mathrm{~km}^{-2}$ & 13.2 & 10.7 & 24.8 \\
\hline q2 runoff rate $*$ & $\mathrm{ls}^{-1} \mathrm{~km}^{-2}$ & 3.3 & 2.8 & 8.9 \\
\hline q98 runoff rate $*$ & $\mathrm{Is}^{-1} \mathrm{~km}^{-2}$ & 43.6 & 45.3 & 73.3 \\
\hline
\end{tabular}

* data from 1995-2015; JJA: Summer (June, July, August); DJF: Winter (December, January, February)

and is a Long-Term Ecological Research (LTER; www.ilter.network) site. At this site, different taxonomic groups and numerous abiotic variables associated with freshwater and floodplain ecosystems are continuously monitored. The Ammer catchment in the Alpine region ("Alpine"; EEA, 2009), is an extensively monitored TERENO (TERestrial ENvironmental Observatories; www.tereno.net) site. The in-catchment variability of topography, climate, and hydrology increases from North (Treene) to South (Ammer) (Table 1, Figure 1).
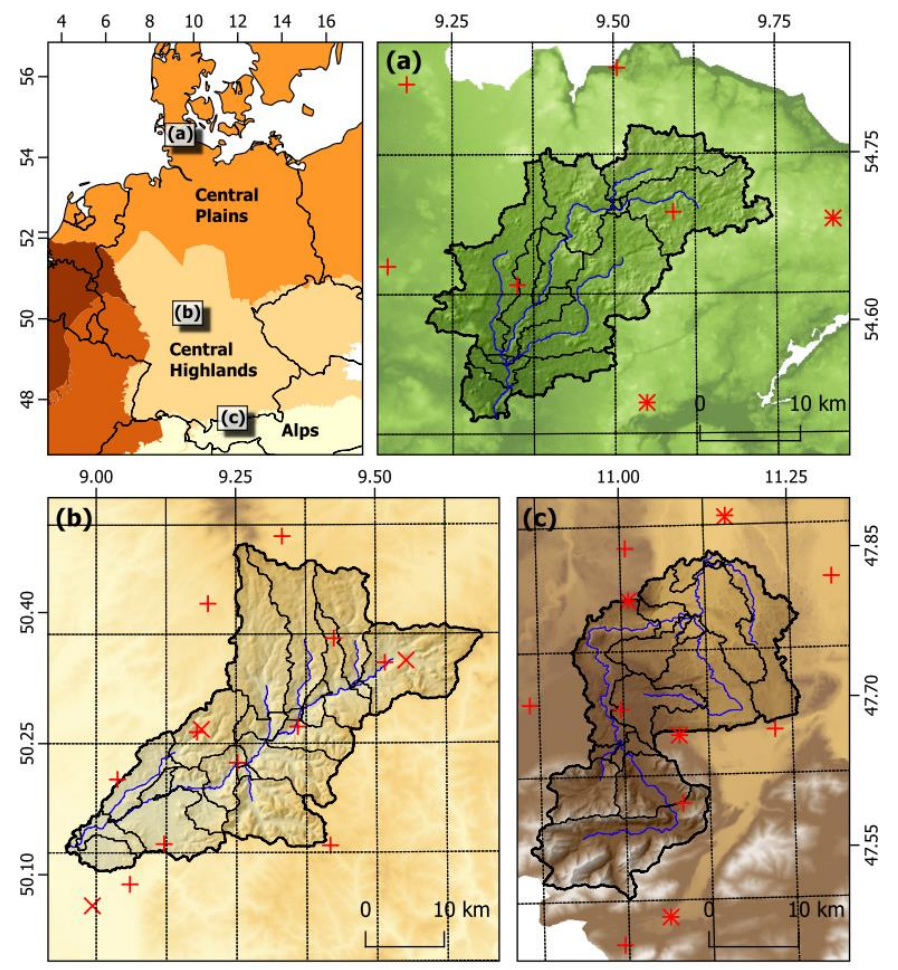

Elevation [mASL]

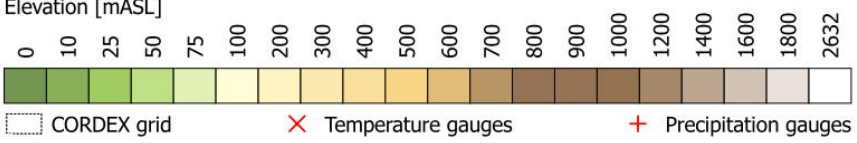


Figure 1. Catchments overview map with ecoregions (EEA 2009); (a) Treene; (b) Kinzig; (c) Ammer including elevation, the EURO-CORDEX grid and precipitation and temperature gauges

Table 2 Thirty-two IHA flow indicators considered in this study, according to Richter et al. (1996)

\begin{tabular}{|c|c|c|c|c|}
\hline Group & Indicator & Description & Abbreviation & Unit \\
\hline $\begin{array}{l}\text { Monthly } \\
\text { Mean (MM) }\end{array}$ & ma12-23* & Mean flow value for Month 1-12 & $\begin{array}{l}\text { Q av Jan - } \\
\text { Q av Dec }\end{array}$ & $\mathrm{m}^{3} / \mathrm{s}$ \\
\hline \multirow{12}{*}{$\begin{array}{l}\text { Magnitude } \\
\text { and duration } \\
(\mathrm{MAG})\end{array}$} & $d l 1$ & Annual minimum 1-day average flow & $Q \min 1 d$ & $\mathrm{~m}^{3} / \mathrm{s}$ \\
\hline & $d 12$ & Annual minimum 3-day average flow & $Q \min 3 d$ & $\mathrm{~m}^{3} / \mathrm{s}$ \\
\hline & $d l 3$ & Annual minimum 7-day average flow & $Q \min 7 d$ & $\mathrm{~m}^{3} / \mathrm{s}$ \\
\hline & $d \mid 4$ & Annual minimum 30-day average flow & Q min 30d & $\mathrm{m}^{3} / \mathrm{s}$ \\
\hline & dl5 & Annual minimum 90-day average flow & Q min $90 d$ & $\mathrm{~m}^{3} / \mathrm{s}$ \\
\hline & dh1 & Annual maximum 1-day average flow & Q $\max 1 d$ & $\mathrm{~m}^{3} / \mathrm{s}$ \\
\hline & dh2 & Annual maximum 3-day average flow & $Q \max 3 d$ & $\mathrm{~m}^{3} / \mathrm{s}$ \\
\hline & dh3 & Annual maximum 7-day average flow & Q $\max 7 d$ & $\mathrm{~m}^{3} / \mathrm{s}$ \\
\hline & dh4 & Annual maximum 30-day average flow & Q max 30d & $\mathrm{m}^{3} / \mathrm{s}$ \\
\hline & dh5 & Annual maximum 90-day average flow & Q max 90d & $\mathrm{m}^{3} / \mathrm{s}$ \\
\hline & dh15 & Duration of flow events above 75th percentile & Days high Q & $d$ \\
\hline & dl16 & Duration of flow events below 25th percentile & Days low Q & $d$ \\
\hline \multirow[t]{2}{*}{ Timing (TIM) } & $\mathrm{tl} 1$ & Julian date of annual minimum & Day Q min & $d$ \\
\hline & th1 & Julian date of annual maximum & Day Q max & $d$ \\
\hline Frequency & fh1 & No. flow events above 75th percentile & No. high Q & - \\
\hline$(\mathrm{FRE})$ & $\mathrm{fl1}$ & No. flow events below 25th percentile & No. low Q & - \\
\hline \multirow[t]{4}{*}{ Rate (RAT) } & ra1 & Mean change in flow for days of positive change & delta Q pos & $\mathrm{m}^{3} / \mathrm{s}$ \\
\hline & ra3 & Mean change in flow for days of negative change & delta Q neg & $\mathrm{m}^{3} / \mathrm{s}$ \\
\hline & ra5 & Ratio of days of flow being higher than previous day & Rise rate & - \\
\hline & ra10 & Ratio of days of flow being lower than previous day & Fall rate & - \\
\hline
\end{tabular}

* represents $12 \mathrm{IHA}$

\subsection{Hydrological indicators}

Richter et al. (1996) developed the indicators of hydrologic alteration (IHA) which, in their basic set, are 32 ecologically relevant hydrological metrics classified into five groups (Table 2). IHA describe the hydrological regime regarding the timing, frequency, magnitude, duration and rate of discharge events.

\subsection{Hydrological models}

The Soil and Water Assessment Tool (SWAT, Arnold et al. 1998) in the version SWAT3S (Pfannerstill et al. 2014a, Guse et al. 2016) is used in this study. SWAT is a semi-distributed hydrological model that divides the model domain into subbasins, which are furthermore split into Hydrological Response Units (HRUs) of equal land use, soil and slope. In this study, the Plains catchment was divided into 13, the Highlands catchment into 20 and the Alpine catchment into 15 subbasins. For each HRU, SWAT calculates the daily water balance and transfers the outflow from surface runoff, interflow and two groundwater aquifers of each $\mathrm{HRU}$ to the reach through which the water is routed to the catchment outlet.

SWAT was calibrated in the three catchments using Latin Hypercube sampling of the parameter space, as implemented in Pfannerstill et al. (2014b), which leads to three different parameterizations in the three catchments. Best models were selected using a multi-objective function which incorporated the 32 IHA (Table 2). This is required since deriving IHA from simulated flow time series include uncertainties (Vigiak et al. 2018, Vis et al. 2015) which can 
be reduced through a tailored model optimization incorporating the IHA into the optimization process (Kiesel et al. 2017, Pool et al. 2017). The optimized model represents a trade-off Table 3 EURO-CORDEX models and versions used in this study

\begin{tabular}{lllll}
\hline ID & GCM & GCMshort & RCM & RCMshort \\
\hline 1 & CNRM-CERFACS-CNRM-CM5 & CNRM & CLMcom-CCLM4-8-17 & CLMcom \\
2 & CNRM-CERFACS-CNRM-CM5 & CNRM & CNRM-ALADIN53 & CNRM \\
3 & CNRM-CERFACS-CNRM-CM5 & CNRM & SMHI-RCA4 & SMHI \\
4 & ICHEC-EC-EARTH & ICHEC & CLMcom-CCLM4-8-17 & CLMcom \\
5 & ICHEC-EC-EARTH & ICHEC & DMI-HIRHAM5 & DMI \\
6 & ICHEC-EC-EARTH & ICHEC & KNMI-RACMO22E & KNMI \\
7 & ICHEC-EC-EARTH & ICHEC & SMHI-RCA4 & SMHI \\
8 & IPSL-IPSL-CM5A-MR & IPSL & IPSL-INERIS-WRF331F & IPSL \\
9 & IPSL-IPSL-CM5A-MR & IPSL & SMHI-RCA4 & SMHI \\
10 & MOHC-HadGEM2-ES & MOHC & CLMcom-CCLM4-8-17 & CLMcom \\
11 & MOHC-HadGEM2-ES & KOHC & KNMI-RACMO22E & KNMI \\
12 & MOHC-HadGEM2-ES & MOHC & CLMI-RCA4 & SMHI \\
13 & MPI-M-MPI-ESM-LR & MPI & MPI-CSC-REMO2009v1 & CLMcom \\
14 & MPI-M-MPI-ESM-LR & MPI & MPI-CSC-REMO2009v2 & MPI2 \\
15 & MPI-M-MPI-ESM-LR & MPI & SMHI-RCA4 & SMHI \\
16 & MPI-M-MPI-ESM-LR & MPI & &
\end{tabular}

between all IHAs, where each indicator (Table 2) was given equal weight. When optimizing for low- or high flows separately, indicators not considered in the calibration process can show deviations of up to $100 \%$, which does not occur when including all indicators (Kiesel et al. 2017). The parameterization can hence be considered balanced between high- and low-flow conditions. Regarding typical hydrological performance metrics, the models show good (Alpine catchment) to very good (Plains- and Highland catchments) performances in KlingGupta-Efficiencies (KGE, Kling et al. 2012) of $0.61-0.94$ (calibration) and $0.74-0.91$ (validation). For a detailed model setup and optimization procedure description, please refer to Kiesel et al. (2017).

\subsection{Climate change data}

16 datasets of GCM+RCM from EURO-CORDEX are used in this study (Table 3). No likelihood of occurrence is assigned to the RCPs (Van Vuuren et al. 2011). However, the CORDEX database had different data availability for the RCPs: RCP 2.6 was available for less than $50 \%$ of the RCP 4.5- and 8.5-scenarios and RCP 6.0 was missing altogether. To obtain a homogeneous dataset, and still consider the uncertainty in future emissions, we chose the RCP 4.5 and 8.5 (henceforth designated as RCP45 and RCP85). The parameters "precipitation" as well as "minimum-" and "maximum daily near surface air temperature" were downloaded in daily time step and highest grid resolution (i.e. $0.11^{\circ}$ ). From these grids, the time series from each CORDEX scenario were extracted from the grid cells where the original climate station was located.

\subsection{Bias correction}


Climate models often provide biased representations of observed time series, emphasizing the need for bias correction, especially in regional climate scenarios that are used to assess climate change impacts on streamflow using watershed-scale hydrologic models (Muerth et al.

2013).

Table 4 Bias correction methods for precipitation and temperature, their combination in the hydrological model and short description

\begin{tabular}{llll}
\hline Precipitation & Temperature & Combination & Description \\
\hline Linear scaling (LS) & Linear scaling & pLS+tLS & Adjust monthly mean \\
& $($ LS) & & $\begin{array}{l}\text { Adjust monthly mean, } \\
\text { monthly frequency } \\
\text { distribution mapping }\end{array}$ \\
$\begin{array}{l}\text { Distribution mapping } \\
(\text { DM) }\end{array}$ & pDM+tDM & Adjust monthly mean, \\
Local intensity scaling & Linear scaling & & wet-day frequency, \\
(LIS) & $($ LS) & pLIS+tLS & precipitation intensity \\
Power transformation & Variance scaling & Adjust monthly mean \\
(PT) & (VS) & PPT+tVS & and variance \\
No correction & No correction & pNO+tNO & Raw CORDEX data \\
(NO) & (NO) & & \\
\hline
\end{tabular}

Since bias correction methods are however controversially discussed and may alter the actual climate change signal (Ehret et al. 2012), we evaluated the impact of different bias correction algorithms as well as raw climate model data (NO BC) on streamflow. The bias-correction methods used for both precipitation and temperature are: linear scaling (LS) and distribution mapping (DM, also denoted as quantile mapping), for precipitation: local intensity scaling (LIS) and power transformation (PT), and for temperature: variance scaling (VS). LIS, PT, and DM were combined with LS to ensure monthly mean values match. Four BC-combinations of the six methods were selected based on their ability to account for differences in statistical parameters. The selected $\mathrm{BC}$-combinations for precipitation and temperature and the main characteristics of the $\mathrm{BC}$ algorithms are shown in Table 4 and were applied using an adapted version of the software CMhyd (Rathjens et al. 2016). A detailed description of each method including an in-depth discussion of advantages and disadvantages is given in Teutschbein and Seibert (2012).

\subsection{Quantifying and reducing uncertainties}

We aimed at projecting changes in $\mathrm{IHA}$, and therefore developed a method to quantify and reduce the uncertainty in depicting the IHA. Therefore, the IHA were calculated from hydrological simulations with observed climate ("baseline") and from hydrological simulations with all combinations of climate model and BC ("hindcasted") for the time period 2005-14 ("2010"). The uncertainty of the simulations was quantified by comparing hindcasted to baseline IHA. Therefore, we applied a multi-objective function using all IHA: We normalized the IHA values through feature scaling over all hindcasted combinations and the baseline (32 normalization procedures). For each combination, the Euclidean Distance (ED) between hindcasted and baseline was calculated for the 32 normalized indicators. The smaller the ED, 
the better hindcasted and baseline simulations match (where $E D=0$ is ideal, and $E D=\sqrt{32}$ worst). ED of the combinations were ordered ascendingly within each ecoregion. We refrained from using arbitrary cutoff values (e.g. 10\% of the best ED values) but decided to base the uncertainty reduction on the slope of the ED distribution. The point of inflection is used as the cutoff value since the subsequent differences in ED of the combinations are getting
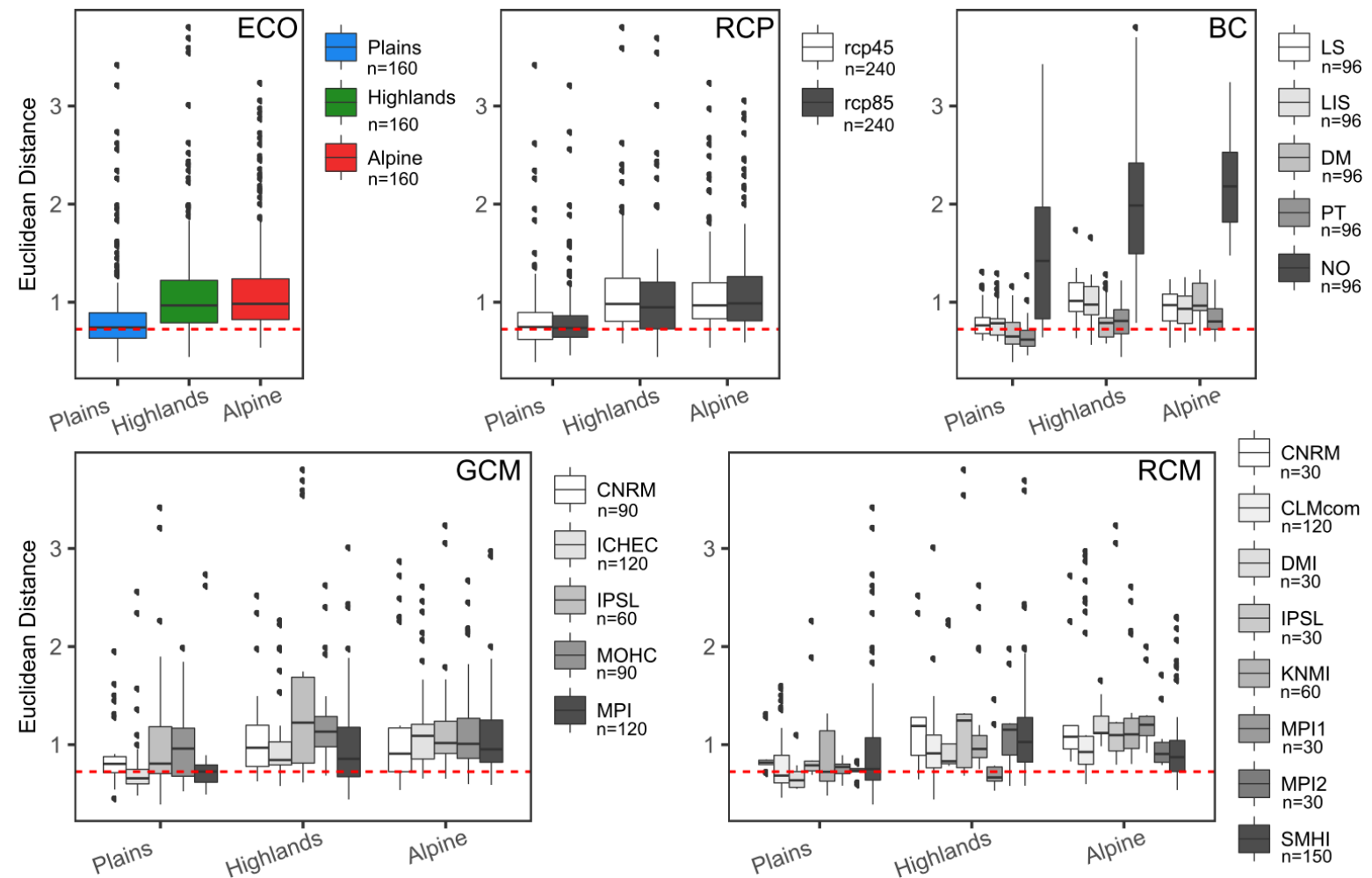

Figure 2. ED distribution grouped according to ecoregion (ECO), RCP, BC, GCM and RCM within each ecoregion, number below legend keys shows the number of points per boxplot, horizontal dashed lines marks the ED cutoff values which is defined in Figure 3

below the inflection point and larger after the point of inflection. Therefore, we fitted a fifthorder Taylor polynomial function through the points and derived the points of inflection (Christopoulos, 2014). All combinations below these points were chosen as the best combinations within each ecoregion.

\subsection{Climate change impact assessment}

We used the selected combinations for a climate change impact assessment on the IHA. IHA values were calculated for the years 2045-54 ("2050") and 2085-94 ("2090") and compared to the 2010 hindcasted indicator values of the same combination. ANOVA and Tukey Honest Significant Difference tests were carried out with a cutoff $p$-value of $5 \%$ to distinguish significant from not-significant projected IHA changes. In climate change studies, 30-year time periods are typically used for characterizing climate change (Maraun et al. 2017). However, for this study, ten-year time periods are chosen to enable a direct usage of the projections for ecological studies, since for those, the investigation period is usually chosen based on the life span of the investigated species (Jourdan et al. 2018). This ranges between one (e.g. most 
macroinvertebrates) to ten years (e.g. freshwater fish), of which we chose the longest period. Still, decadal variability may influence the projection using ten-year periods and therefore, we analyzed a second set of time slices (2035-44: "2040" and 2075-84: “2080") to check if the results are robust across decades.

\section{RESULTS}

3.1. Quantifying and reducing uncertainties

The overall model performance (indicated as the ED) is best in the Plains- and similar in the Highland- and Alpine ecoregion (Figure 2-ECO). The ED for RCP45 and RCP85 are comparable (Figure 2-RCP). The raw CORDEX data (no bias correction) reveals a North-South gradient since the performance of some combinations in the catchment in the Plains is equally high as bias-corrected combinations in other catchments (Figure 2-BC). Interestingly, the skills of BC methods vary among the ecoregions. For instance, LS and LIS perform reasonable in the Plains-, but worse than others in the Highland- and Alpine ecoregion. DM performs well in the Plains- and Highland ecoregion, but weak in the Alpine. Only PT performs good constantly. Both GCM and RCM show no clear pattern (Figure 2-GCM-RCM). While most models perform well in one ecoregion with low ED values and low variability (e.g. CNRM, ICHEC and MPI; CNRM, IPSL, MPI1 and MPI2 in the Plains ecoregion), they do not so elsewhere. The different groups ( $E C O, R C P, B C, G C M, R C M$ ) lead to a varying range of the $E D$, where a higher range is associated with higher uncertainty. The lowest 25th- and highest 75th- percentile in ED of each group and their range is summarized in Table 5. The smaller the range, the lower the impact of choosing a particular model or method from the respective group on ED and viceversa. As can be seen, the choice of the RCP (0.49) matters least for the agreement between baseline and hindcasted hydrological indicators, while the decision to carry out or not carry out bias correction is the strongest influencing factor (1.78). However, if a choice is made to carry out bias correction, the selection between the different bias correction methods introduces less uncertainty (0.44)) than any other choice, which are declining in relevance from GCM (0.62), ecoregion (0.61) to RCM (0.57) and RCP (0.49).

All 160 combinations per ecoregion (Figure 2) are ordered by increasing ED (Figure 3) and shown as small circles. Each fitted fifth-order Taylor polynomial function (Figure 3, dashed line) follows these ordered values closely, which represents a good fit. Their inflection points are defined as the ED cutoff values that divide the distribution into more- and less uncertain combinations. These cutoff values are at $E D=0.72$ ( 20 combinations) in the Alpine-, $E D=0.73$ (31 combinations) in the Highland- and $E D=0.72$ (70 combinations) in the Plains ecoregion.

The best combinations below the cutoff value are shown in Figure 4. The methods and models within each ecoregion are scaled to $100 \%$ within each group so that the ecoregions with more selected combinations do not mask ecoregions with fewer combinations. Since some models occur more often than others in the CORDEX dataset ( $n=x x$ in legends of Figure 2-GCM-RCM), the occurrences were normalized so that models with higher initial occurrences are not favored. An example for that is IPSL in the GCM group, which is favored over the ICHEC model in the Highland catchment. Both have five occurrences below the ED threshold (not shown), 
Table 5. Minimum $25^{\text {th }}$ and maximum $75^{\text {th }}$ percentile of ED within each group of models and methods, including the resulting ED-range

\begin{tabular}{lccccc}
\hline & BC & GCM & ECO & RCM & RCP \\
\hline minimum of 25th percentile & 0.64 & 0.67 & 0.63 & 0.68 & 0.70 \\
maximum of 75th percentile & $2.42(1.08)^{*}$ & 1.29 & 1.24 & 1.25 & 1.19 \\
Range of 25 and 75 percentiles & $1.78(0.44)^{*}$ & 0.62 & 0.61 & 0.57 & 0.49 \\
\hline
\end{tabular}

* number in brackets: without 'no Bias Correction'

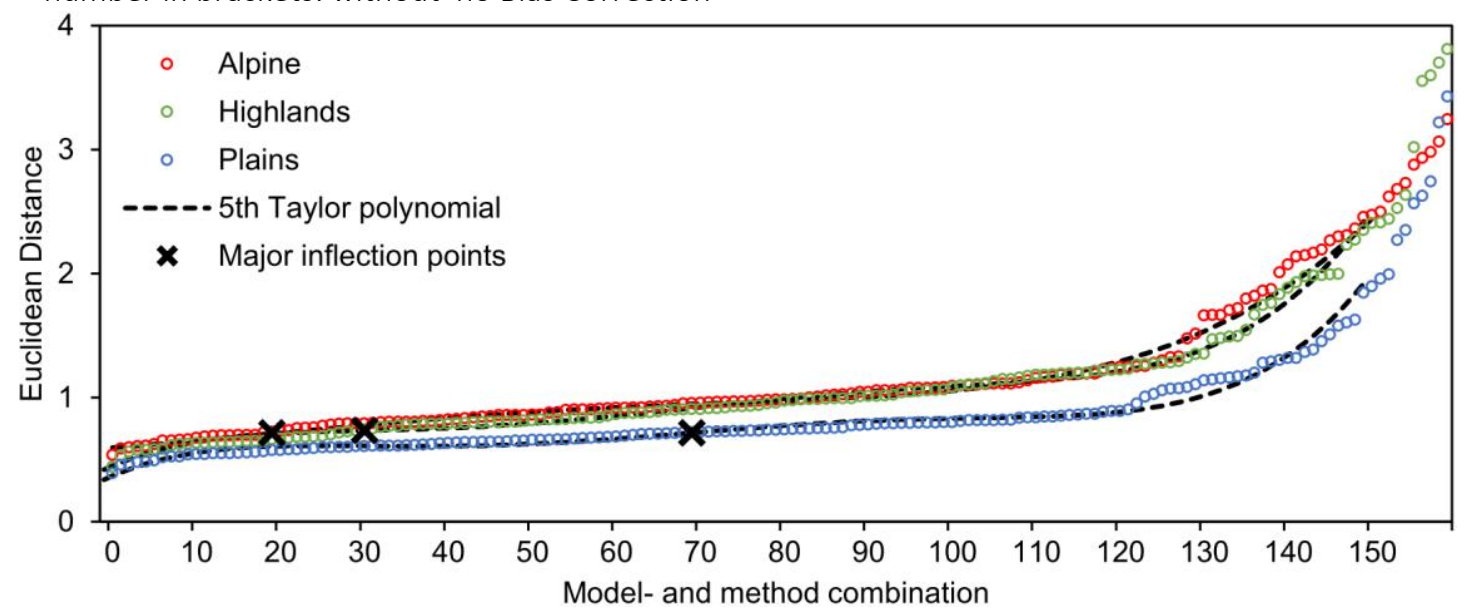

Figure 3. ED of all combinations in increasing order, $5^{\text {th }}$ order fitted Taylor polynomial with point of inflection, grouped by catchment

but IPSL's only 60 instead of 120 (ICHEC) source combinations lead to a higher percentage occurrence. The bias correction method that performs best and consistently well across the ecoregions is PT, while other methods show strengths and weaknesses in different regions. LIS and LS perform similar in the Plains and Highland Ecoregion. In the Plains, NO bias correction is selected within the best performing combinations. In Figure 4, more RCP85 combinations were selected than RCP45, especially in the Highland ecoregion. In the GCM group, CNRM performs best in the Alpine, the ICHEC model in the Plains and MPI in the Highland ecoregion. Regarding the RCM, only CLMcom and SMHI are amongst the selected models in the Alpine and MPI1 performs best in the Highland ecoregion. In the Plains ecoregion, multiple models perform almost equally well. To back up the results regarding the bias correction and to ensure these impacts are not due to non-linearity in the hydrological models, we separately analyzed the precipitation and temperature values before and after bias correction. Figure 5 a confirms that PT and DM generally perform best in matching historical precipitation patterns across the three regions. For temperature (Figure 5b), no clear difference between the methods are apparent, but it is obvious that the raw CORDEX temperature data consistently underestimates 


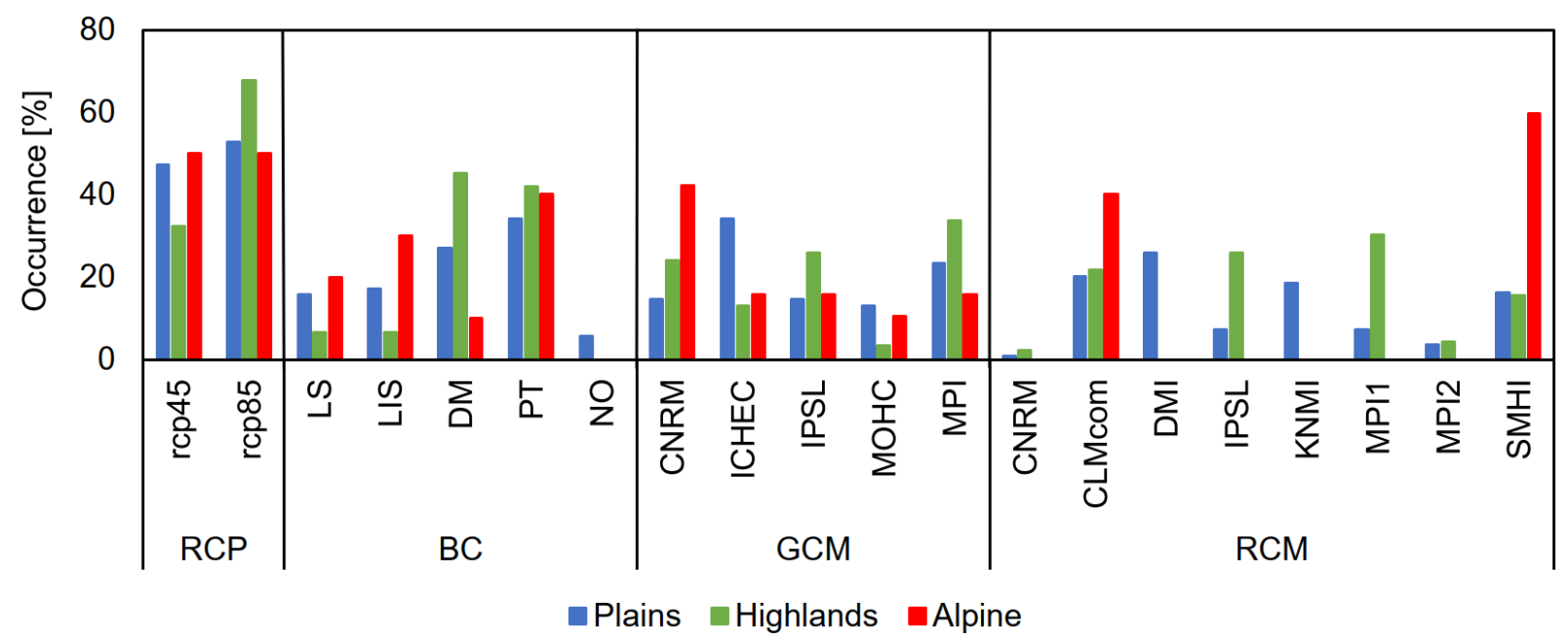

Figure 4. Occurrences in percent per group and ecoregion of the selected combinations below the ED cutoff values; for abbreviations of models, see Table 3

(a)
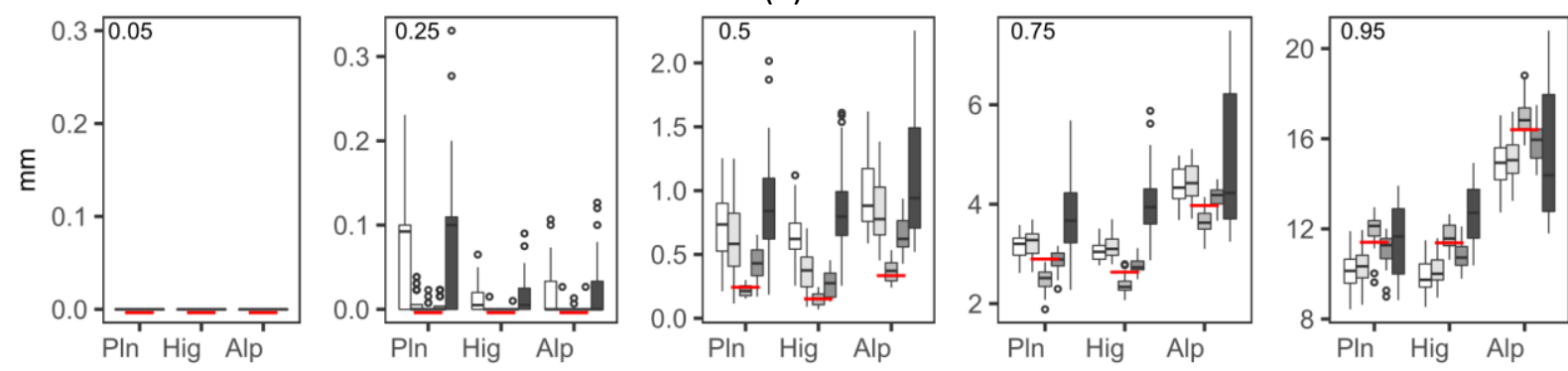

自

(b)
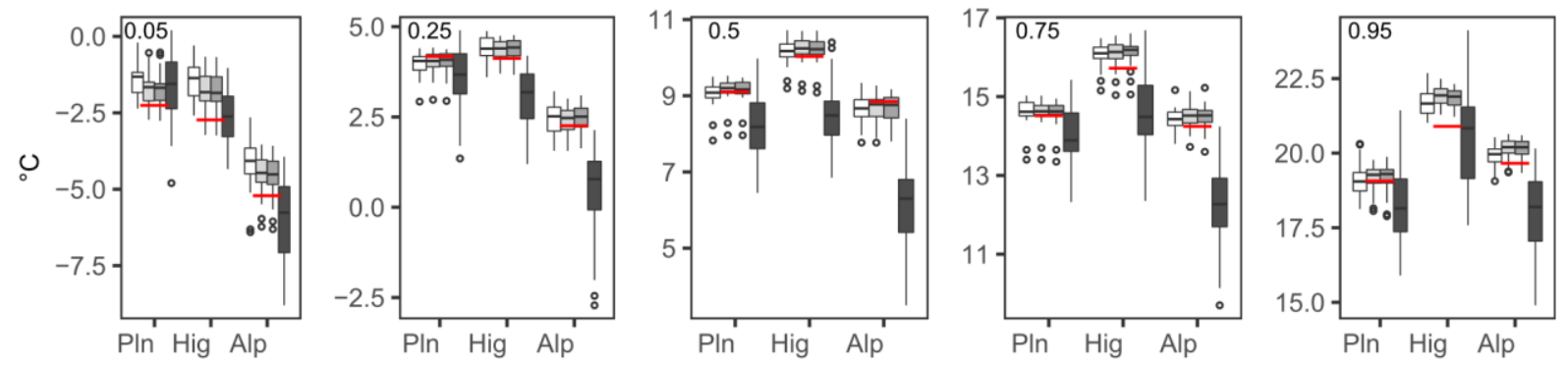

\section{它 Ls}

Figure 5. Impact of bias correction methods on 0.05-, 0.25-, 0.5-, 0.75- and 0.95 percentile of precipitation (a) and temperature (b) over the hindcasted period 2004-2014, red line marks the observed value

temperatures, apart from the coldest temperatures in the Plains and Highland ecoregion (Figure 5b, 0.05 percentile). The impact of the BC selection method is stronger for precipitation than for temperature.

\subsection{Climate change impacts}

Figures 6, 7 and 8 show the baseline indicator values (column 2010) and changes in absolute values for 2050 and 2090 period of all combinations. This allows a visual interpretation of the 
variability in the baseline simulations and the predictions. Generally, the restriction to the combinations below the ED cutoff value show a closer fit to the observations and slightly decrease the variability in the predictions. Statistically significant changes in indicators compared to the baseline are marked with triangles and occur within each indicator group in all ecoregions. The center of the triangles shows the change in indicator (ensemble mean). The indicator's units of change and description is provided in Table 2. Significant and robust projected changes of IHA are: In the Plains catchment (Figure 6), fewer extremes (2090, fh1+fl1, RCP45+85) but more intense (2090, dh1-5 RCP85) and longer flood events (2050 RCP45, dh15, 2090 RCP45+85) as well as higher average flow in February (2050+2090, ma13, $\mathrm{RCP} 45+85)$ and a reduction in late autumn and early winter (2050+2090, ma21+ma22, RCP45+85) are projected. In both the Plains and Highland catchment (Figure 7), a slight increase in the rise rate and reduction in the fall rate $(2050+2090$, ra5+ra10, RCP45+85) are projected. Additionally, in the Highland catchment, fewer extremes $(2050+2090$, fh $1+f \mid 1$, RCP45+85) but longer high flows (2090, dh15, RCP45+85) are projected to occur. In the Alpine catchment

(Figure

$8)$, earlier low 

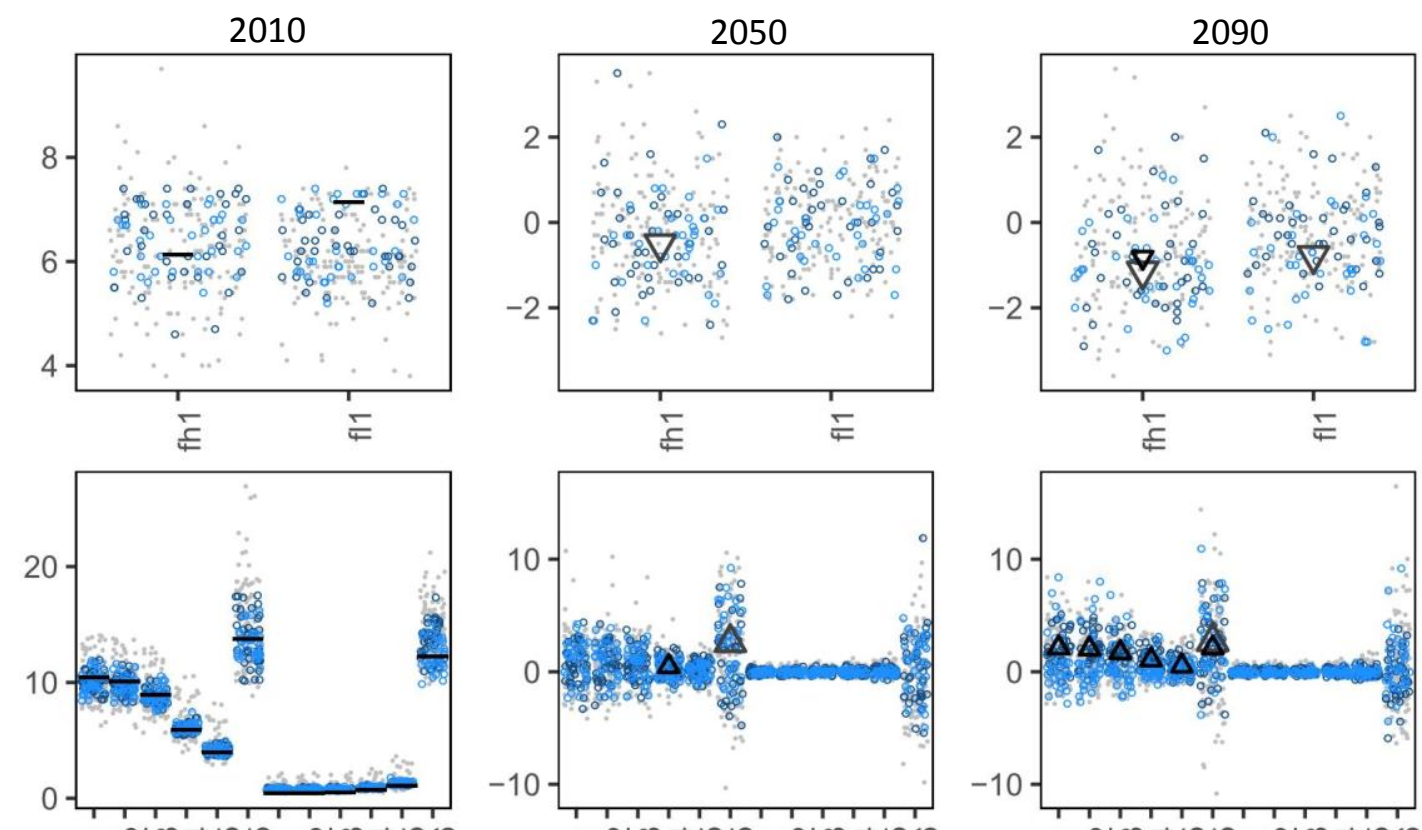

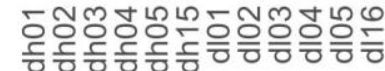
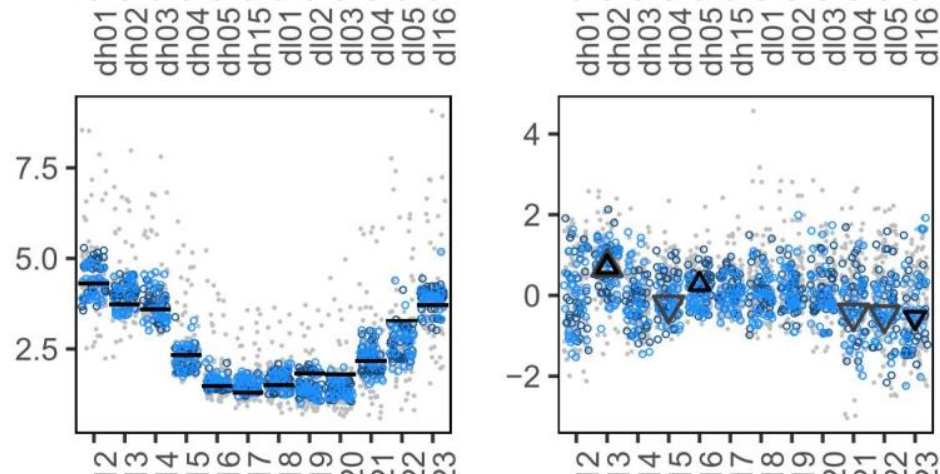

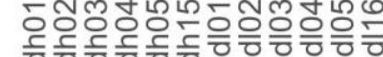

FЕE
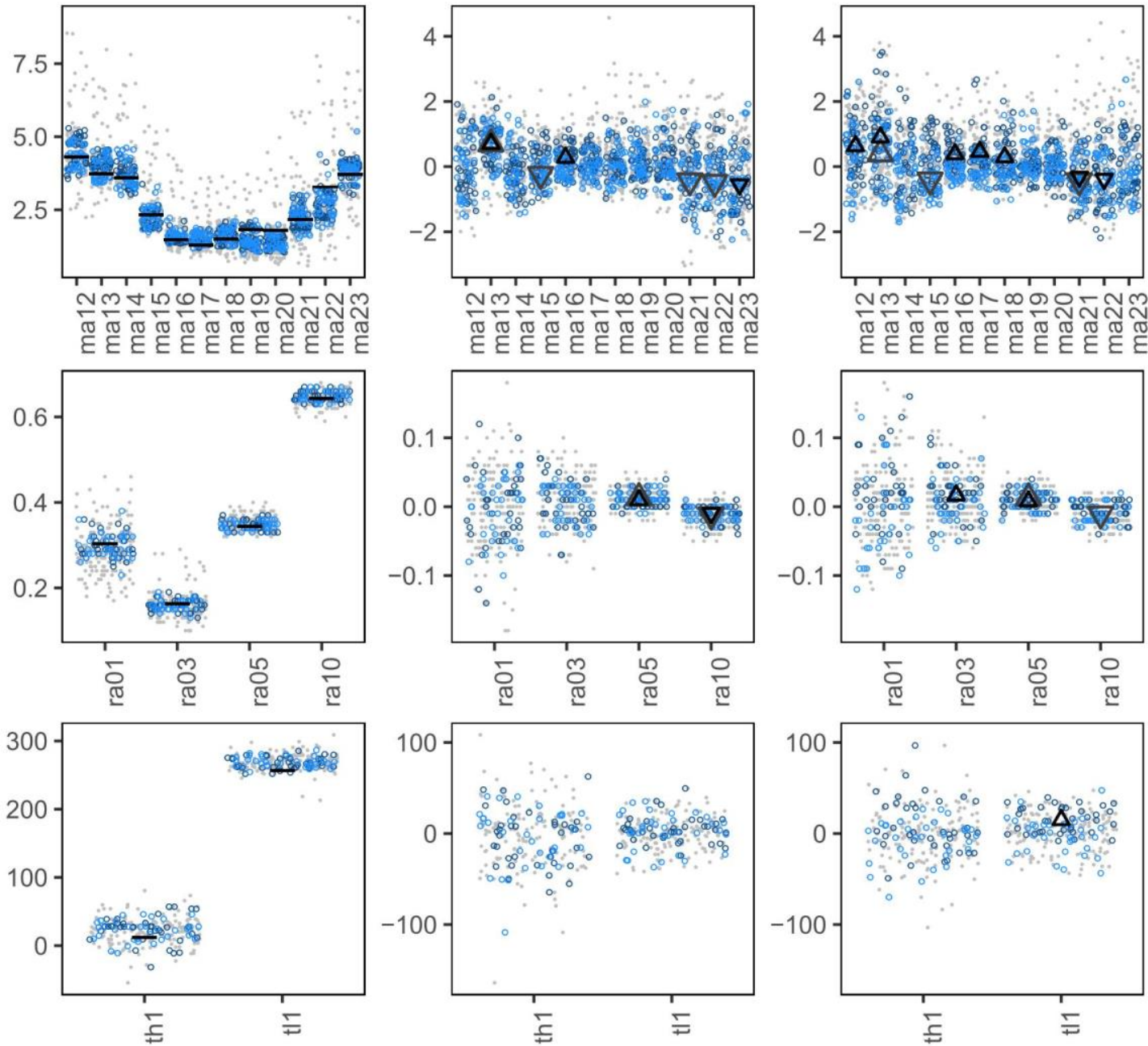

- Observed

- Selected combinations rcp45 $\Delta \nabla$ Significant increase/decrease rcp45

- All combinations

- Selected combinations rcp85

$\Delta \nabla$ Significant increase/decrease rcp85

Figure 6. IHA values for the three time periods in the Plains ecoregion. 2050 and 2090 show the changes in comparison to hindcasted 2010 in the unit of the indicator (Table 2, incl. description) 
2010
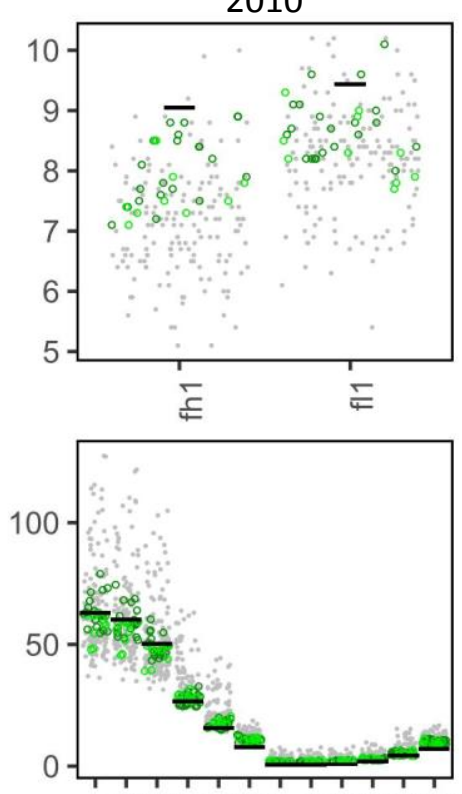

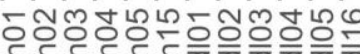

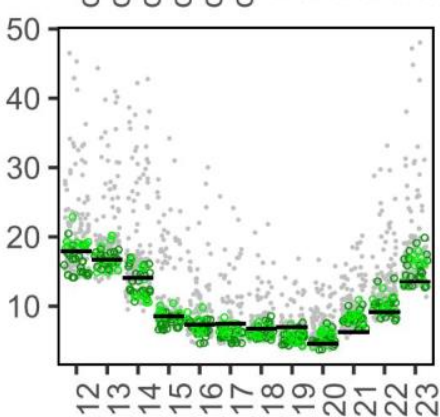

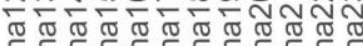
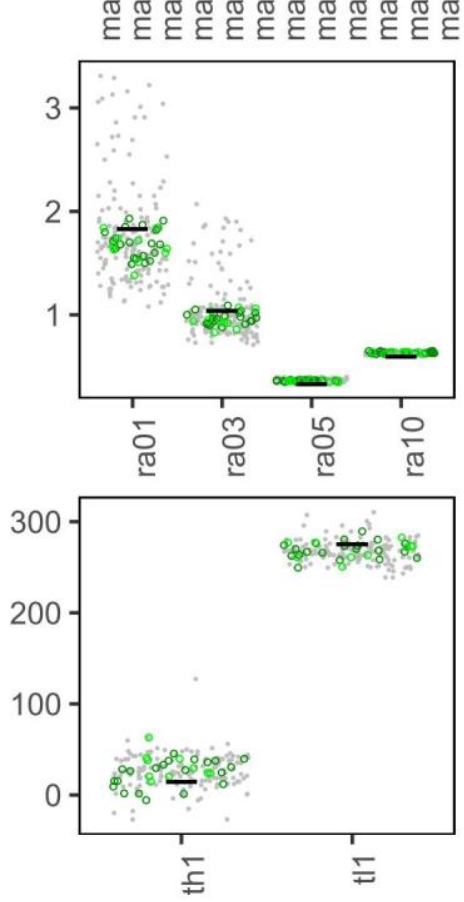

- Selected combinations rcp45

- Observed

- All combinations o Selected combinations rcp85 $\Delta \boldsymbol{\nabla}$ Significant increase/decrease rcp85

2050
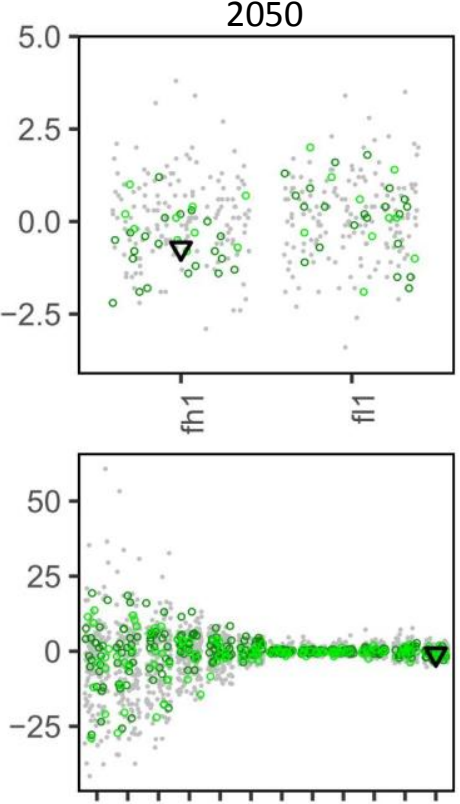

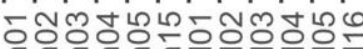

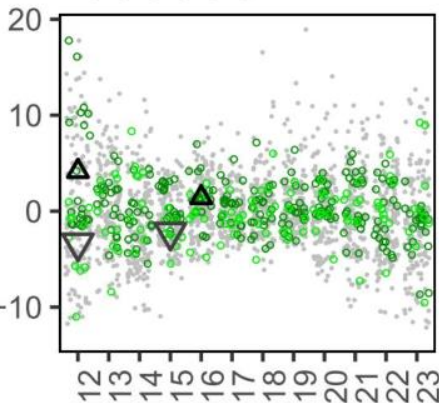

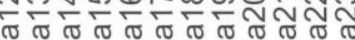

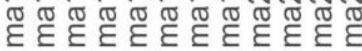
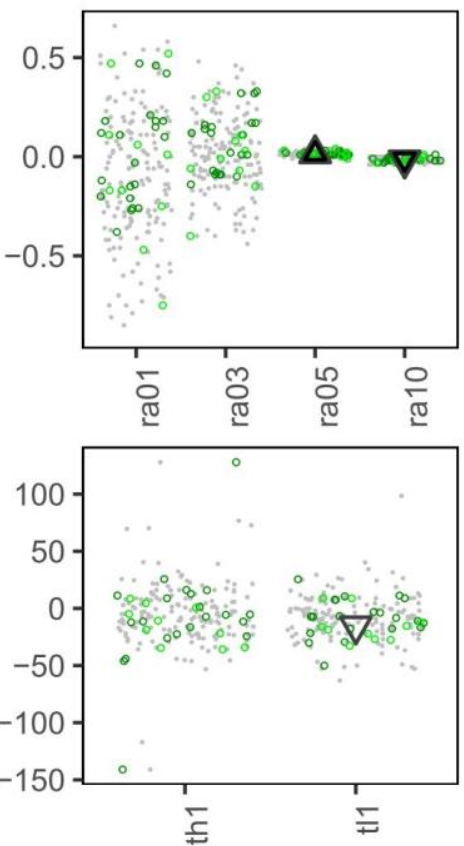
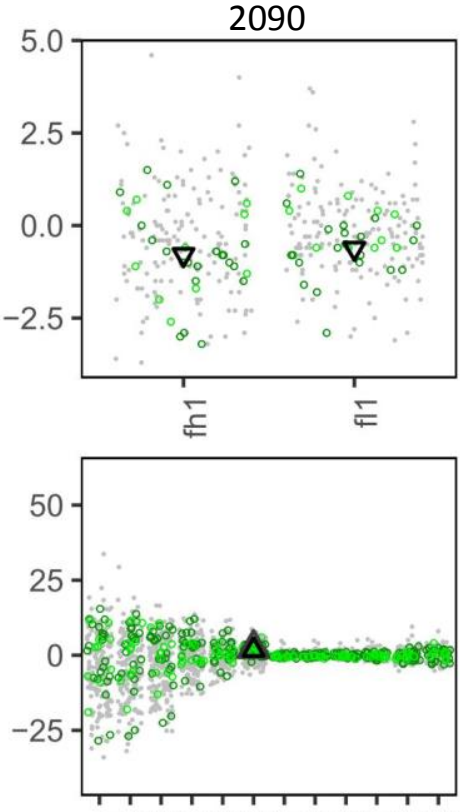

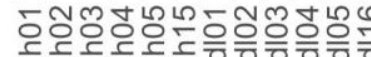
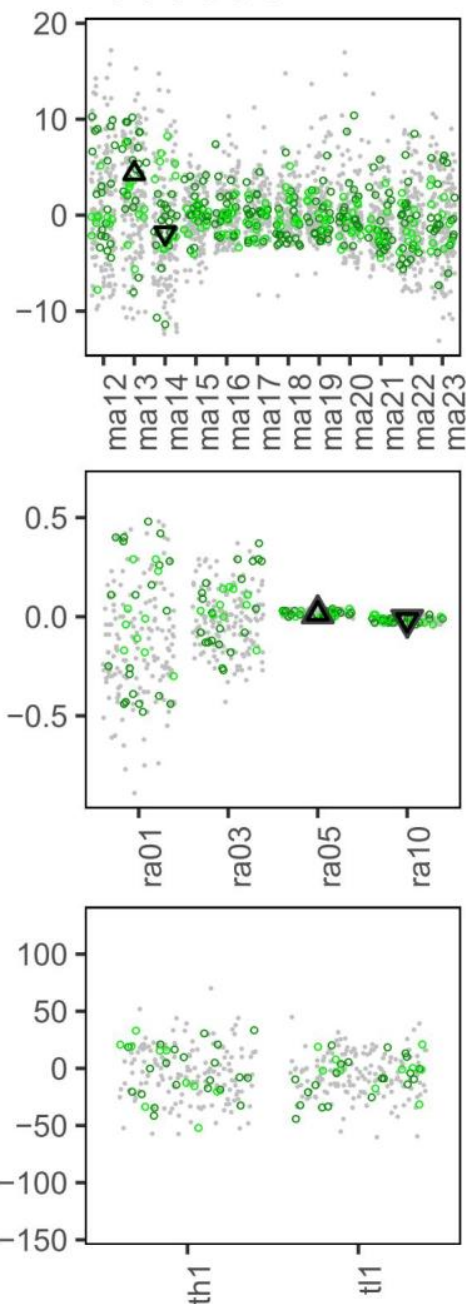

$\Delta \nabla$ Significant increase/decrease rcp45

Figure 7. IHA values for the three time periods in the Highland ecoregion. 2050 and 2090 show the changes in comparison to hindcasted 2010 in the unit of the indicator (Table 2, incl. description) 

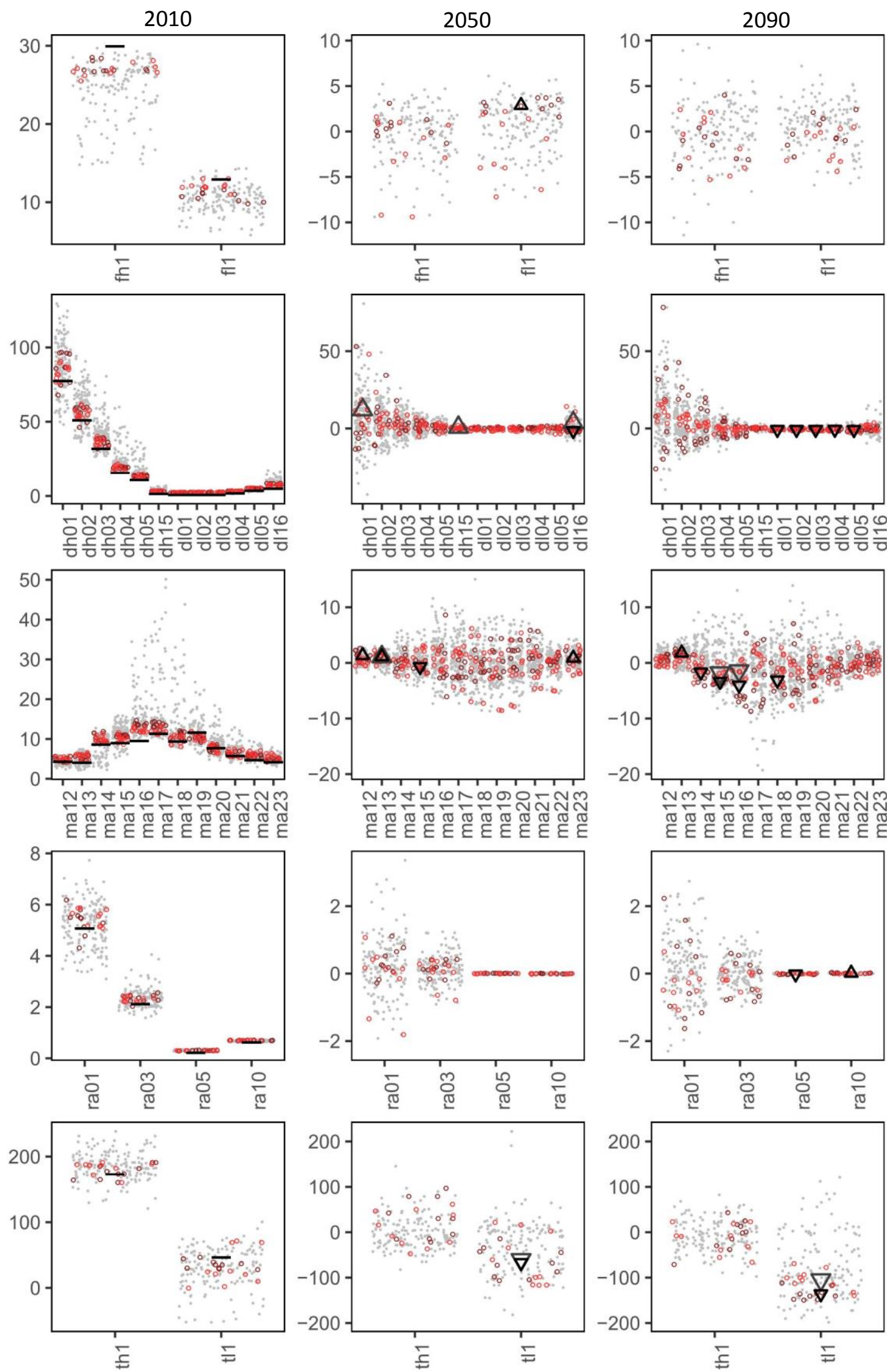

- Observed

- Selected combinations rcp45 $\Delta \nabla$ Significant increase/decrease rcp45

- All combinations $\bullet$ Selected combinations rcp85 $\Delta \boldsymbol{\nabla}$ Significant increase/decrease rcp85

Figure 8. IHA values for the three time periods in the Alpine ecoregion. 2050 and 2090 show the changes in comparison to hindcasted 2010 in the unit of the indicator (Table 2, incl. description) 
Table 6. Relative changes in percent of the 32 IHA for 2050 and 2090 in comparison to hindcasted (Baseline) 2010 which shows the absolute value; grey cells mark no significant change where only the direction of change (- negative, + positive) is given; blue cells mark positive- and orange cells negative significant change; results show significant mean change as an ensemble over the selected combinations

\begin{tabular}{|c|c|c|c|c|c|c|c|c|c|c|c|c|c|c|c|c|c|}
\hline & & & & & lai & & & & & lla & & & & & Alps & & \\
\hline & & & 2010 & & & & & 2010 & & & & & 2010 & & 50 & & 90 \\
\hline & Indicator & & 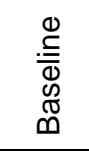 & $\begin{array}{l}\frac{L}{\sim} \\
\stackrel{0}{0}\end{array}$ & $\begin{array}{l}\infty \\
\infty \\
0 \\
0 \\
0\end{array}$ & 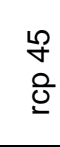 & $\begin{array}{l}\infty \\
\infty \\
0 \\
0\end{array}$ & 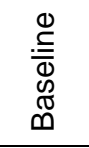 & $\begin{array}{l}\text { fo } \\
\text { 운 }\end{array}$ & $\begin{array}{l}10 \\
\infty \\
0 \\
0\end{array}$ & $\begin{array}{l}\frac{1}{8} \\
0 \\
0\end{array}$ & $\begin{array}{l}10 \\
\infty \\
0 \\
0 \\
0\end{array}$ & 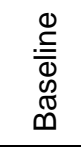 & $\begin{array}{l}\text { ? } \\
\text { 은 }\end{array}$ & $\begin{array}{l}\infty \\
\infty \\
\stackrel{0}{\underline{0}}\end{array}$ & 10 & $\begin{array}{l}\infty \\
\infty \\
0 \\
0\end{array}$ \\
\hline & Q av $J$ & & 4.4 & - & + & 1 & 14 & 18.4 & -18 & 23 & - & 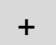 & 4.8 & + & 28 & + & + \\
\hline & $Q$ av Feb & & 3.8 & 18 & 18 & 10 & 23 & 17.2 & - & + & + & 25 & 4.6 & 24 & 25 & + & 39 \\
\hline & $Q$ av Mar & & 3.7 & - & - & - & + & 14.6 & + & - & + & -13 & 9.1 & - & + & - & -18 \\
\hline & Q av Apr & & 2.4 & -10 & + & -17 & + & 9.1 & -24 & + & - & + & 9.6 & + & -7 & -19 & -35 \\
\hline శ్ల్ & Q av May & & 1.6 & - & 18 & - & 24 & 7.8 & - & 18 & - & + & 10.1 & + & - & -14 & -40 \\
\hline 2 & Q av Jun & $\bar{\omega}$ & 1.4 & - & + & - & 33 & 8.0 & - & + & - & + & 11.9 & + & - & + & - \\
\hline$\overline{\bar{E}}$ & Q av Jul & $\varepsilon$ & 1.6 & - & + & - & 18 & 7.2 & + & + & + & - & 10.0 & + & - & - & -31 \\
\hline & Q av Aug & & 1.9 & + & + & + & - & 7.5 & - & + & + & - & 12.2 & - & + & - & - \\
\hline & Q av Sep & & 1.9 & + & + & + & + & 5.0 & + & 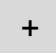 & - & + & 8.2 & - & + & - & - \\
\hline & Q av Oct & & 2.3 & -19 & - & -19 & -14 & 6.8 & - & + & - & - & 6.3 & - & + & - & - \\
\hline & Q av Nov & & 3.4 & -14 & - & - & -11 & 9.7 & + & - & - & - & 5.2 & - & + & - & - \\
\hline & Q av Dec & & 3.8 & - & -14 & - & + & 14.0 & + & - & - & - & 4.7 & + & 19 & - & + \\
\hline & Q & & 0.8 & - & - & - & - & 2.0 & - & - & - & - & 2.0 & - & + & - & -35 \\
\hline & $Q \min 3 d$ & & 0.8 & - & - & - & - & 2.1 & - & - & - & - & 2.1 & - & + & - & -34 \\
\hline & $Q \min 7 d$ & & 0.8 & - & - & - & + & 2.2 & - & - & - & - & 2.2 & - & + & - & -32 \\
\hline & $Q \min 30 d$ & & 1.0 & - & + & - & - & 3.3 & - & + & - & - & 3.1 & - & + & - & -20 \\
\hline 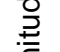 & $Q \min 90 d$ & $\frac{\omega}{\infty}$ & 1.4 & - & + & - & - & 5.8 & - & + & - & - & 4.9 & - & + & - & -16 \\
\hline క్ & $Q \max 1 d$ & & 10.7 & + & + & + & 20 & 64.5 & - & - & - & - & 78.8 & 15 & + & + & + \\
\hline & $Q \max 3 d$ & & 10.4 & + & + & + & 20 & 61.5 & - & - & - & - & 52.3 & + & + & + & + \\
\hline & Q ma & & 9.2 & + & + & + & 18 & 51.6 & - & - & - & + & 33.2 & + & + & + & + \\
\hline & $Q \max 30 d$ & & 6.2 & + & 7 & + & 17 & 28.0 & - & + & - & + & 17.0 & + & + & - & - \\
\hline & $Q \max 90 d$ & & 4.3 & + & + & + & 12 & 17.0 & - & + & + & + & 12.2 & + & + & - & - \\
\hline & Days high $Q$ & 㐫 & 14.1 & 18 & + & 19 & 15 & 9.3 & - & + & 24 & 19 & 3.0 & 25 & - & + & + \\
\hline & Days low Q & & 12.6 & + & + & + & - & 8.6 & - & -11 & + & + & 6.3 & 59 & -23 & + & + \\
\hline$\varepsilon$ & Day $Q$ min & 齐 & 261 & + & + & - & 4 & 279 & -4 & - & - & - & 50 & -16 & -18 & -29 & -37 \\
\hline & Day Q max & & 16 & - & - & - & + & 19 & - & - & - & - & 176 & + & + & - & - \\
\hline 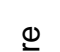 & Nr high $Q$ & 7 & 6.2 & -8 & - & -18 & -13 & 9.1 & - & -8 & - & -9 & 30.2 & - & + & - & - \\
\hline$\overline{\mathbf{\square}}$ & Nr low $Q$ & & 7.2 & - & - & -11 & - & 9.5 & + & + & + & -7 & 13.2 & - & 22 & - & - \\
\hline & delta Q pos & 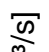 & 0.3 & - & - & - & + & 1.9 & - & + & + & - & 5.2 & . & + & - & + \\
\hline$\stackrel{5}{\pi}$ & delta $Q \mathrm{n}$ & & 0.2 & 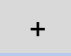 & + & + & 10 & 1.1 & $\begin{array}{lll}+ & \end{array}$ & + & + & + & 2.2 & + & + & 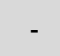 & - \\
\hline & Rise rate & & 0.4 & 4 & 3 & 4 & 2 & 0.4 & 4 & 4 & 4 & 4 & 0.3 & + & + & + & -6 \\
\hline & Fall rate & & 0.7 & -2 & -1 & -2 & & 0.6 & -3 & -2 & -2 & -3 & 0.7 & - & - & - & 2 \\
\hline
\end{tabular}

flows (2050+2090, tl1, RCP45+85), less average flow in spring (2090, ma14-ma16, RCP45+85), and higher average flow in late winter $(2050+2090$, ma12+ma13, RCP45+85) are projected. 
In addition, the selected combinations below the ED cutoff value have been used as an ensemble (mean over all combinations) to predict relative changes in future streamflow and IHA. Table 6 summarizes the results for all indicators and ecoregions, both RCPs and time periods in percent changes from baseline to the respective future time period. $23 \%$ of the projections (88/384) show significant changes. The highest number of significant changes of indicators are observed in the Plains catchment (39), followed by the Alpine catchment (28) and the Highland catchment (21). On average, RCP 85 shows $75 \%$ more significant changes in indicators than RCP45. In 2090,38\% more indicators are subject to significant changes than in 2050. The average percentage change over all indicators, ecoregions and RCPs is $\pm 16 \%$. The second analysis for the 2040 and 2080 time slices is used to assess the decadal stability of the projections. The results for 2040 and 2080 (supplementary material, Table S1) lead to a similar pattern of change as the 2050 and 2090 results (Table 6). The agreement in the direction of change between both analyses is $91 \%$, indicating that the results are not impacted by decadal variability.

\section{DISCUSSION}

\subsection{Quantifying and reducing uncertainties}

According to our results, uncertainties show an increasing trend from the Plains-, over the Highland- to the Alpine catchments. This finding is in agreement with Kotlarski et al. (2014) who found a better performance of the CORDEX dataset for both temperature and precipitation in mid-Europe than in the Alpine region. In our case, the Plains catchment, where the raw climate model data performed best, is also subject to the highest number of significant changes in indicators, revealing that the predictions are least uncertain there. On the other hand, the Highland and Alpine catchment are subject to less significant changes, indicating that climate models agree less which cannot be improved through bias corrections. The RCP85 and RCP45 scenarios are different from 2006 onwards, allowing a careful comparison between the two scenarios regarding the agreement with the observations since that year. In that regard, the RCP85 model results depict recent streamflow slightly better than RCP45. This result is supported by observations that the actual greenhouse gas emissions of the last decade have followed the RCP85 trajectory closer than the RCP45 scenario (Sanford et al. 2014).

Carrying out any bias correction greatly reduces the ED values and their range. However, their performances vary among the catchments. The Plains catchment has the best result based on the raw CORDEX data, which also leads to best overall performance. There, the climate models seem to be able to reproduce the precipitation pattern best, which is characterized by more, yet less intense rainfall events (Figure S1a, 0.95 percentile). In both the Highland and Alpine catchments, the raw CORDEX data causes strong overestimations of streamflow in winter and summer. Using bias corrected climate in these regions means, that the original CORDEX data is altered more than in the Plains catchment. Therefore, the derived climate change signal in these regions will be more uncertain, especially since the $B C$ methods assume stationarity of the BC parameters over the decades (Ehret et al. 2012). Similar to Teutschbein and Seibert (2013), we see the tendency that more complex bias correction methods are preferable over simpler methods. 
Uncertainties introduced into the simulations by the GCMs and RCMs choices vary across ecoregions. The GCMs show a different performance in the different ecoregions, but all GCMs are represented in the best simulations. Some GCM are particularly skilled in depicting certain regions, but no model can be suggested for general use in all ecoregions: Plains and Highland have the same best GCM (ICHEC and MPI), while the best model in the Alpine (CNRM) performs only average in the other ecoregions. The RCMs have a stronger spatial dependence than the GCMs, and show a heterogeneous distribution of performance. Only for the Plains catchment, all RCMs are represented in the best model runs. This is reduced to only two RCMs present in the best simulations in the Alpine catchment, indicating that RCMs have to be more specialized to depict the more erratic precipitation processes in the Alpine ecoregion.

The uncertainty introduced by hydrological model choice and its parameterization was not considered in this study. Hagemann et al. (2013) found a decisive influence of the hydrological model choice on runoff, with a focus on the higher latitudes (50 and higher), however, two more recent studies (Addor et al. 2014 and Melsen et al. 2018) found that the uncertainty due to the hydrological model choice or parameterization are usually overruled by the climate change projections. The latter studies show, that the choice of the GCM (Melsen et al. 2018) and RCM (Addor et al. 2014) are usually the main source of uncertainty.

\subsection{Climate change impacts}

The change in hydrological indicators shows a diverse picture with significant changes occurring in all catchments and indicator groups. This shows, that climate change is projected to impact all major hydrological flow components. In the Plains catchment, the shift towards higher spring and lower autumn average flows may be triggered by an increase in temperature leading to higher evaporation, especially in summer. Due to the strong groundwater influence, catchment response to decreasing flow in late autumn is delayed. This may also lead to the projected, though not significant, reduction in annual low flows, increase in the duration of low flows (flow is longer below the $25^{\text {th }}$ percentile) and decrease in the number of low flow events (flow passes the $25^{\text {th }}$ percentile less often). Highest flows in the baseline occur during the first four months of the year in the Plains catchment. Those are projected to increase further, which is also represented in the increase of annual maximum flows and the duration of high flows. This observation is most likely due to increasing precipitation during the winter months. The findings presented here for the Plains catchment are qualitatively supported by a recent regional analysis (DWD, 2017).

The change in the rise- and fall rate of the hydrograph in both the Plains and Highland catchment is small, yet consistent. Possibly, less water storage in the shallow and deep groundwater aquifers result in a faster flow recession which may decrease the duration of receding flows (the fall rate) and subsequently, increase the duration of rising flows (the rise rate). However, the impacts are rarely significant and not consistent across time periods and RCPs in the Highland catchment. The projected increase in the duration of high discharge events can be linked to an increase in heavy rainfall in the central German mountain range (Adelphi et al. 2015). 
In the Alpine catchment, most changes in the flow metrics can be traced back to the snow processes which respond to the consistent increase of temperatures over time and from the RCP45 to the RCP85. Therefore, significant changes show a higher magnitude for the RCP85 than for the RCP45 and for 2090 than 2050. A consistent decrease of average flows in the spring months of March to May as well as an increase in the average flows in the late winter months of January and February can be explained through earlier occurring and faster snowmelt. This is linked to the reduction of low flows towards the end of this century. In the baseline, the lowest flow occurs during late winter and early spring. The projected shift of the lowest flow to mid-winter (2050) and late autumn (2090) is connected to the snowmelt processes as well: The earlier occurrence of snowmelt increases the lowest flows, occurring in late winter in the baseline. Due to this shift towards earlier groundwater recharge, groundwater storages in the catchments are depleted earlier and together with an increased evapotranspiration, late autumn flows are reduced (Barnett et al. 2005).

Significant changes with a high ecological impact are considered to be the alteration in extremes (Poff and Zimmerman, 2010). These are the 16\% to 35\% reduction in low flows in the Alps, the shift of the lowest flows from spring to late autumn and the $12 \%$ to $20 \%$ increase in high flows in the Plains catchment.

\section{CONCLUSION}

To evaluate robust climate change impacts on ecologically relevant streamflow indicators, we (1) carried out a comprehensive uncertainty analysis using a broad range of climate change forcings and five bias correction methods in three ecoregions, we (2) reduced the uncertainty by selecting the combinations that depicted baseline hydrological indicators best, and we (3) used these combinations to carry out an analysis of climate change-induced alterations of IHA for the period 2050 and 2090.

We can confirm findings in previous studies, that the choice of the GCM and RCM significant uncertainties and the performance of the climate models varies among different regions. Therefore, we suggest that all available GCM and RCM should be initially screened when carrying out climate impact studies. Regarding bias correction methods, we stress the importance of including the raw climate change data into the full analysis to assess the agreement of the original climate change data to the baseline. This yields important information regarding the uncertainty in the prediction, which was also highest for the regions where raw climate data performed worst. If bias correction is carried out, we also suggest to test different methods, while Distribution Mapping and Power Transformation seem to be the better choice rather than simpler methods.

Acknowledging the previously described uncertainty and studies, it is important to select simulations with the lowest uncertainty to predict future streamflow changes. We stress that the uncertainty reduction method should incorporate the IHA to be analyzed. This is important, because choosing simulations based on different criteria, e.g. standard hydrological performance criteria, does not prevent the choice of simulations where IHA are depicted unrealistically.

The changes in IHA under climate change are predicted using an ensemble of the previously selected simulations. Despite the fact that only the best-performing simulations were used in 
the analysis, we stress the importance to carry out statistical tests for a significance assessment of the evaluated change in indicator values. Only about a quarter of indicators were subject to significant changes, which varied across ecoregions, RCPs and time periods. The significant changes were different in different ecoregions and due to the complex interaction between precipitation and temperature change and catchment properties. This raises the question of spatial stability of the projected changes in IHA within and across borders of ecoregions, e.g. as continental or global studies of climate change impact on hydrology have shown for runoff (Hagemann 2013). The projected changes in IHA provide an important basis to assess climate change impacts and related uncertainties on freshwater species that depend on certain flow conditions (Kakouei et al. 2018).

\section{ACKNOWLEDGEMENTS}

This study was funded through the "GLANCE" project (Global change effects on river ecosystems; 01LN1320A) supported by the German Federal Ministry of Education and Research (BMBF). AG was funded through the "BAUM" project supported by the German Federal Ministry of Environment, Nature Conservation, Building and Nuclear Safety (03DAS074). SCJ further acknowledges funding through the "AQUACROSS" project (Knowledge, Assessment, and Management for AQUAtic Biodiversity and Ecosystem Services aCROSS EU policies; 642317) supported by the European Union's Horizon 2020 Programme for Research, Technological Development and Demonstration. For the discharge, topographic and land use data, we thank the state agencies of Schleswig-Holstein (Agency for Coastal Defense, National Park and Marine Conservation, LKN-SH; State Surveying Office, LVA; State Agency for Agriculture, Environment and Rural Areas, LLUR), Hessian (Hessian Agency for Nature Conservation, Environment and Geology, HLNUG; Hessian Administration for LandManagement and Land-Registry, HVBG) and Bavaria (Bavarian Agency for Environment, LfU). We also thank the German Weather Service (DWD) and the World Climate Research Programme's Working Group on Regional Climate, and the Working Group on Coupled Modelling, former coordinating body of CORDEX and responsible panel for CMIP5 including the climate modelling groups (listed in Table 1 of this paper) for the climate data and the Federal Institute for Geosciences and Natural Resources (BGR) for the soil data. We acknowledge the support for fieldwork in the Rhine-Main-Observatory (Kinzig catchment) by Peter Haase, Senckenberg and the supply of the Kinzig reservoir release rules by Paul Brinkmann from ARCADIS. The authors thank Björn Guse for valuable discussions. We also thank two anonymous reviewers, whose comments have considerably improved an earlier version of the manuscript.

\section{REFERENCES}

Addor N, Rössler O, Köplin N, Huss M, Weingartner R, Seibert J (2014) Robust changes and sources of uncertainty in the projected hydrological regimes of Swiss catchments. Water Resources Research 50: 75417562

Adelphi, PRC, EURAC (2015) Vulnerabilität Deutschlands gegenüber dem Klimawandel. Umweltbundesamt. Climate Change 24/2015, Dessau-Roßlau 
Arnold JG, Srinivasan R, Muttiah RS, Williams JR (1998) Large area hydrologic modelling and assessment part I: model development. Journal of the American Water Resources Association 34(1): 73 - 89

Barnett TP, Adam JC, Lettenmaier DP (2005) Potential impacts of a warming climate on water availability in snow-dominated regions. Nature 438(17): 303-309

Christopoulos D (2017) R-package RootsExtremalnflections, https://CRAN.R-

project.org/package=RootsExtremalnflections

Clark MP, Wilby RL, Gutmann ED, Vano JA, Gangopadhyay S, Wood AW, Fowler AJ, Prudhomme C, Arnold JR, Brekke LD (2016) Characterizing Uncertainty of the Hydrologic Impacts of Climate Change. Curr Clim Change Rep 2, 55-64. DOI 10.1007/s40641-016-0034-x

Domisch S, Portmann FT, Kuemmerlen M, O'Hara RB, Johnson RK, Davy-Bowker J, Bækken T, Zamora-Muñoz C, Sáinz-Bariáin M, Bonada N, Haase P, Döll P, Jähnig SC (2017) Using streamflow observations to estimate the impact of hydrological regimes and anthropogenic water use on European stream macroinvertebrate occurrences. Ecohydrology 10:e1895-n/a. 10.1002/eco.1895

Donnelly C, Greuell W, Andersson J, Gerten D, Pisacane G, Roudier P, Ludwig F (2017) Impacts of climate change on European hydrology at 1.5, 2 and 3 degrees mean global warming above preindustrial level. Climatic Change 143: $13-26$

DWD (2017) Klimareport Schleswig-Holstein, Deutscher Wetterdienst, Offenbach am Main, Deutschland: 1-44

EEA (2009) Ecoregions for Rivers and Lakes. European Environmental Agency

Ehret U, Zehe E, Wulfmeyer V, Warrach-Sagi K, Liebert J (2012) Should we apply bias correction to global and regional climate model data?. Hydrology and Earth System Sciences 16: 3391-3404

Fohrer, N., Schmalz, B., 2012. The UNESCO ecohydrology demonstration site Kielstau catchment - sustainable water resources management and education in rural areas. Hydrologie und Wasserbewirtschaftung 56 (4), 160168.

Guse B, Kail J, Radinger J, Schröder M, et al (2015) Eco-hydrologic model cascades: Simulating land use and climate change impacts on hydrology, hydraulics and habitats for fish and macroinvertebrates. Science of the Total Environment 533: 542-556

Guse B, Pfannerstill M, Strauch M, Reusser DE, et al (2016) On characterizing the temporal dominance patterns of model parameters and processes. Hydrological Processes 30: 2255-2270

Hagemann S, Chen C, Clark DB, Folwell S, et al (2013) Climate change impact on available water resources obtained using multiple global climate and hydrology models. Earth System Dynamics 4: 129-144, doi:10.5194/esd-4-129-2013

Jacob D, Petersen J, Eggert B, Alias A, et al (2014) EURO-CORDEX: new high-resolution climate change projections for European impact research. Regional Environmental Change 14: 563-578

Jourdan J, O'Hara RB, Bottarin R, Huttunen K-L, et al (2018) Effects of changing climate on European stream invertebrate communities: A long-term data analysis. Science of the Total Environment 621: 588-599.

doi:10.1016/j.scitotenv.2017.11.242 
Kakouei K, Kiesel J, Kail J, Pusch M, Jähnig SC (2017) Quantitative hydrologic preferences of benthic stream invertebrates in Germany. Ecological Indicators 79: 163-172

Kakouei K, Kiesel J, Domisch S, Irving KS, Jähnig SC, Kail J (2018) Projected effects of climate-change-induced flow alterations on stream macroinvertebrate abundances. Ecology and Evolution 00: 1-17 https://doi.org/10.1002/ece3.3907

Kiesel J, Guse B, Pfannerstill M, Kakouei K, Jähnig SC, Fohrer N (2017) Improving hydrological model optimization for riverine species. Ecological Indicators 80: 376-385

Kling H, Fuchs M, Paulin M (2012) Runoff conditions in the upper Danube basin under an ensemble of climate change scenarios. Journal of Hydrology 424-425: 264-277

Kotlarski S, Keuler K, Christensen B, Colette A, et al (2014) Regional climate modeling on European scales: a joint standard evaluation of the EURO-CORDEX RCM ensemble. Geoscientific Model Development 7: 1297-1333

Lytle DA, Poff NL (2004) Adaptation to natural flow regimes. Trends in Ecology and Evolution 19(2): 94-100

Maraun DT, Shepherd G, Widmann M, Zappa G, et al (2017) Towards process-informed bias correction of climate change simulations. Nature Climate Change 7(11): 764-773

Melsen L, Addor N, Mizukami N, Newman A, Torfs P, Clark M, Uijlenhoet R, Teuling R (2018) Mapping (dis)agreement in hydrological projections. Hydrology and Earth System Sciences Discussions (accepted), https://doi.org/10.5194/hess-2017-564

Muerth MJ, Gauvin St-Denis B, Ricard S, Velázquez JA, et al (2013) On the need for bias correction in regional climate scenarios to assess climate change impacts on river runoff. Hydrology and Earth System Sciences 17: 1189-1204. doi:10.5194/hess-17-1189-2013

Nemec J, Schaake J. 1982. Sensitivity of water resources systems to climate variation. Hydrological Sciences Journal 27, 327-343.

Pfannerstill M, Guse B, Fohrer N (2014a) A multi-storage groundwater concept for the SWAT model to emphasize nonlinear groundwater dynamics in lowland basins. Hydrological Processes 28(22): 5599-5612

Pfannerstill M, Guse B, Fohrer N (2014b) Smart low flow signature metrics for an improved overall performance evaluation of hydrological models. Journal of Hydrology 510: 447-458

Poff NL, Zimmerman JKH (2010) Ecological responses to altered flow regimes: a literature review to inform the science and management of environmental flows. Freshwater Biology 55: 194-2015

Pool S, Vis MJP, Knight RR, Seibert J (2017) Streamflow characteristics from modeled runoff time series importance of calibration criteria selection. Hydrology and Earth System Sciences 21: 5443-5457

Rathjens H, Bieger K, Srinivasan R, Chaubey I, Arnold JG (2016) Documentation for preparing simulated climate change data for hydrologic impact studies. URL: http://swat.tamu.edu/software/cmhyd/

Richter BD, Baumgartner JV, Powell J, Braun DP (1996) A Method for Assessing Hydrologic Alteration within Ecosystems. Conservation Biology 10(4): 1163-1174

Sanford T, Frumhoff PC, Luers A, Gulledge J (2014) The climate policy narrative for a dangerously warming world. Nature Climate Change 4: 164-166 
Teutschbein C, Seibert J (2012) Bias correction of regional climate model simulations for hydrological climatechange impact studies: Review and evaluation of different methods. Journal of Hydrology 456-457: 12-29

Teutschbein C, Seibert J (2013) Is bias correction of regional climate model (RCM) simulations possible for nonstationary conditions? Hydrology and Earth System Sciences 17: 5061-5077

Van Vuuren DP, Edmonds J, Kainuma M, Riahi K, et al (2011) The representative concentration pathways: an overview. Climatic Change 109: 5-31

Vigiak O, Lutz S, Mentzafou A, Chiogna G, et al (2018) Uncertainty of modelled flow regime for flow-ecological assessment in Southern Europe. Science of the Total Environment 615: 1028-1047

Vis M, Knight R, Pool S, Wolfe W, Seibert J (2015) Model Calibration Criteria for Estimating Ecological Flow Characteristics. Water 2015(7): 2358-2381

Wagner PD, Reichenau TG, Kumar S, Schneider K (2015) Development of a new downscaling method for hydrologic assessment of climate change impacts in data scarce regions and its application in the Western Ghats, India. Regional Environmental Change 15: 435-447 


\section{SUPPLEMENTARY MATERIAL}

Table S1. Relative changes in percent of the 32 IHA for 2040 and 2080 in comparison to hindcasted (Baseline) 2010 which shows the absolute value; grey cells mark no significant change where only the direction of change (- negative, + positive) is given; blue cells mark positive- and orange cells negative significant change; results show significant mean change as an ensemble over the selected combinations

\begin{tabular}{|c|c|c|c|c|c|c|c|c|c|c|c|c|c|c|c|c|c|}
\hline & \multirow{3}{*}{ Indicator } & \multirow[b]{3}{*}{ 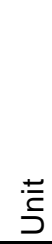 } & \multicolumn{5}{|c|}{ Plains } & \multicolumn{5}{|c|}{ Highlands } & \multicolumn{5}{|c|}{ Alps } \\
\hline & & & \multirow{2}{*}{ 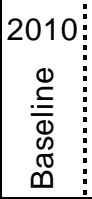 } & \multicolumn{2}{|c|}{2040} & \multicolumn{2}{|c|}{2080} & \multirow{2}{*}{ 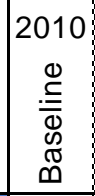 } & \multicolumn{2}{|c|}{2040} & \multicolumn{2}{|c|}{2080} & \multirow{2}{*}{ 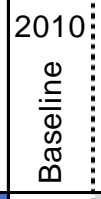 } & \multicolumn{2}{|c|}{2040} & \multicolumn{2}{|c|}{2080} \\
\hline & & & & 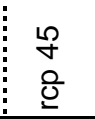 & $\begin{array}{l}L \\
\infty \\
0 \\
\underline{0} \\
\end{array}$ & 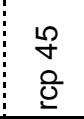 & $\begin{array}{l}10 \\
\infty \\
\stackrel{0}{0} \\
\end{array}$ & & $\begin{array}{l}\stackrel{0}{+} \\
\text { 인 }\end{array}$ & $\begin{array}{l}10 \\
\infty \\
0 \\
0 \\
\end{array}$ & $\begin{array}{l}10 \\
\forall \\
\text { 인 }\end{array}$ & $\begin{array}{l}10 \\
\infty \\
0 \\
\underline{0}\end{array}$ & & \begin{tabular}{l}
$\qquad 0$ \\
\multirow{+}{*}{} \\
인
\end{tabular} & $\begin{array}{l}\infty \\
\infty \\
0 \\
0\end{array}$ & $\begin{array}{l}\text { L } \\
\text { O } \\
\text { 잉 } \\
\end{array}$ & $\begin{array}{l}\infty \\
\infty \\
0 \\
0\end{array}$ \\
\hline \multirow{12}{*}{ 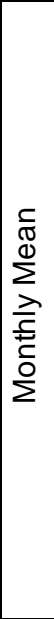 } & Q av Jan & \multirow{12}{*}{$\frac{\bar{c}}{\stackrel{\infty}{\infty}}$} & 4.4 & 9.0 & + & 10.4 & 22.7 & 18.4 & - & 22.7 & + & 29.7 & 4.8 & + & + & 33.0 & 50.2 \\
\hline & Q av Feb & & 3.8 & 20.2 & 11.9 & 10.1 & 19.3 & 17.2 & + & + & - & 17.3 & 4.6 & + & + & 36.8 & 74.8 \\
\hline & Q av Mar & & 3.7 & + & - & - & + & 14.6 & + & -8.9 & - & - & 9.1 & - & + & - & + \\
\hline & Q av Apr & & 2.4 & - & + & -10.2 & 10.3 & 9.1 & - & - & -25.5 & 13.8 & 9.6 & - & - & - & -19.0 \\
\hline & Q av May & & 1.6 & + & 16.0 & - & 16.7 & 7.8 & - & + & - & + & 10.1 & - & - & - & - \\
\hline & Q av Jun & & 1.4 & + & 24.2 & + & 19.7 & 8.0 & - & + & - & + & 11.9 & - & - & + & -23.9 \\
\hline & Q av Jul & & 1.6 & - & 20.6 & - & + & 7.2 & + & - & - & + & 10.0 & - & - & - & -31.9 \\
\hline & Q av Aug & & 1.9 & + & + & + & + & 7.5 & - & + & - & + & 12.2 & - & + & - & - \\
\hline & Q av Sep & & 1.9 & + & + & - & + & 5.0 & + & + & - & + & 8.2 & - & + & - & - \\
\hline & Q av Oct & & 2.3 & - & - & -21.8 & - & 6.8 & + & + & - & + & 6.3 & - & + & - & + \\
\hline & Q av Nov & & 3.4 & + & - & $\begin{array}{l}-12.0 \\
-12.0\end{array}$ & - & 9.7 & + & + & - & 22.6 & 5.2 & - & + & - & 27.7 \\
\hline & Q av Dec & & 3.8 & + & - & - & + & 14.0 & + & + & + & + & 4.7 & + & + & 40.9 & 49.0 \\
\hline \multirow{12}{*}{$\begin{array}{l}\frac{0}{0} \\
\frac{1}{2} \\
\frac{\pi}{5} \\
\stackrel{\pi}{2}\end{array}$} & Qm & \multirow{10}{*}{$\begin{array}{l}\frac{\sigma}{n} \\
\text { है }\end{array}$} & 0.8 & - & - & - & - & 2 & - & - & - & + & 2 & - & - & - & - \\
\hline & $Q \min 3 d$ & & 0.8 & + & - & - & - & 2.1 & - & - & - & + & 2.1 & - & - & - & - \\
\hline & $Q \min 7 d$ & & 0.8 & + & - & - & - & 2.2 & - & - & - & + & 2.2 & - & - & - & - \\
\hline & $Q \min 30 d$ & & 1.0 & + & + & - & + & 3.3 & + & + & - & + & 3.1 & - & - & - & - \\
\hline & $Q \min 90 d$ & & 1.4 & - & + & - & + & 5.8 & - & + & + & + & 4.9 & - & - & - & + \\
\hline & $Q \max 1 d$ & & 10.7 & + & 16.4 & + & 15.0 & 64.5 & - & - & + & + & 78.8 & - & + & + & + \\
\hline & $Q \max 3 d$ & & 10.4 & + & 15.8 & + & 14.8 & 61.5 & - & - & + & + & 52.3 & - & + & + & + \\
\hline & Q m & & 9.2 & + & 14.1 & + & 14.3 & 51.6 & - & - & + & + & 33.2 & - & + & + & + \\
\hline & $Q \max 30 d$ & & 6.2 & + & $0 ?$ & + & 14.9 & 28.0 & + & + & + & 18.2 & 17.0 & - & + & + & - \\
\hline & $Q \max 90 d$ & & 4.3 & 9.7 & 8.2 & + & 12.9 & 17.0 & + & + & - & 17.7 & 12.2 & - & + & - & - \\
\hline & Days high $Q$ & 离 & 14.1 & 18.1 & 14.4 & + & 12.3 & 9.3 & + & 17.7 & + & 27.4 & 3.0 & + & + & + & - \\
\hline & Days low $Q$ & 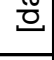 & 12.6 & + & - & + & - & 8.6 & - & - & + & - & 6.3 & + & - & + & -20.5 \\
\hline \multirow{2}{*}{. } & Day Q min & 空 & 261 & + & + & + & 2 & 279 & -4 & -2.4 & - & -3.1 & 50 & -15 & -23 & -23 & -38 \\
\hline & Day Q max & 응 & 16 & - & + & - & - & 19 & - & - & $\begin{array}{l}-5.4 \\
\end{array}$ & - & 176 & - & - & - & + \\
\hline \multirow{2}{*}{ ષ் } & Nr high Q & \multirow{2}{*}{ 工 } & 6.2 & -10.7 & -8.5 & -9.6 & -11.5 & 9.1 & - & -10.2 & - & -13.9 & 30.2 & - & - & - & + \\
\hline & Nr low $Q$ & & 7.2 & - & - & + & -6.1 & 9.5 & + & + & + & + & 13.2 & - & + & + & 16.8 \\
\hline \multirow{4}{*}{ 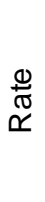 } & delta Q pos & $\frac{w}{\infty}$ & 0.3 & - & + & - & + & 1.9 & + & - & - & + & 5.2 & - & + & - & + \\
\hline & delta $Q$ neg & $\underline{E}$ & 0.2 & + & 8.27 & + & 8.59 & 1.1 & + & + & + & + & 2.2 & - & + & + & + \\
\hline & Rise rate & & 0.4 & 3.72 & 3.32 & 3.81 & + & 0.4 & 4.44 & 5.16 & 3.61 & 4.37 & 0.3 & + & + & + & - \\
\hline & Fall rate & & 0.7 & -1.82 & -1.66 & -1.82 & - & 0.6 & -1.90 & -2.95 & - & -2.49 & 0.7 & - & - & - & + \\
\hline
\end{tabular}

